\title{
AMORA-PRETA (Rubus sp.): OTIMIZAÇÃO DO PROCESSO DE EXTRAÇÃO PARA DETERMINAÇÃO DE COMPOSTOS FENÓLICOS ANTIOXIDANTES ${ }^{1}$
}

\author{
MÁRCIA VIZZOTTO² \& MARINA COUTO PEREIRA ${ }^{3}$
}

RESUMO-Tendo em vista que alguns compostos fenólicos encontrados em amora-preta são benéficos para a saúde humana devido à sua ação antioxidante. Este estudo foi conduzido com o propósito de otimizar o seu processo de extração. As amostras foram submetidas a testes em que variam a relação: amostra:solvente, tempo de maceração, diferentes solventes, misturas de solventes e solventes acidificados. Não houve diferenças nos resultados em relação ao volume de solvente, tempo de maceração, mistura de solventes e acidificação para o conteúdo de compostos fenólicos. Já, dentre os solventes, a acetona foi mais eficiente na extração dos compostos fenólicos. A atividade antioxidante não foi alterada pelo tempo de maceração e pelas misturas de solvente; no entanto, o volume, o tipo de solvente e a acidificação deste afetaram a atividade antioxidante. Termos para indexação: compostos biativos, pequenas frutas, condições de extração.

\section{BLACKBERRY (Rubus sp.): EXTRACTION PROCESS OPTIMIZATION AND DETERMINATION OF PHENOLIC COMPOUNDS ANTIOXIDANTS}

\begin{abstract}
Considering that several phenolic compounds found in blackberry are beneficial to human health because of its antioxidant action, this study was conducted in order to optimize its extraction process for analysis. Samples were subjected to different extraction process: solvent, soaking time, solvent mixtures and acidified solvents. There were no differences in the results for volume of solvent, maceration time, solvent mixtures and acidification for the content of phenolic compounds; however, among the tested solvents, acetone was more efficient for extraction of phenolic compounds. The antioxidant activity was not affected by maceration time and the solvent mixtures; however the volume, the type of solvent and its acidification affected the antioxidant activity.
\end{abstract}

Index terms: bioactive compounds, small fruits, extraction conditions.

\section{INTRODUÇÃO}

O cultivo comercial da amora-preta teve início na Europa, no século 17, quando a cultivar Evergreen foi selecionada a partir de material nativo e, a partir daí, espalhou-se para diversos países. No Brasil, as primeiras plantas foram introduzidas em 1972, pela Embrapa Clima Temperado, de Pelotas (RS), que selecionou cultivares adaptadas, a partir de material oriundo da Universidade de Arkansas (EUA). No Rio Grande do Sul, a amoreira-preta tem tido grande aceitação pelos produtores, devido ao baixo custo de produção, facilidade de manejo, rusticidade e pouca utilização de defensivos agrícolas (ANTUNES, 2002).

Os fitoquímicos, encontrados naturalmente em frutas e hortaliças, apresentam efeitos benéficos sobre a saúde humana, e muitos destes compostos são encontrados em amora-preta, como os ácidos fenólicos (gálico, hidroxibenzoico, cafeico, cumárico, ferúlico e elágico) e seus derivados, e também os flavonoides (catequina, epicatequina, miricetina, quercetina e caempferol) (SELLAPPAN et al., 2002).

Estudos demonstram que extratos de amorapreta apresentam efeitos antimutagênicos (TATE et al., 2006) e anticarcinogênicos para as linhagens humanas de câncer de útero, de cólon (LAZZE et al., 2004), oral, de mama, de próstata (SEERAM et al., 2006) e de pulmão (DING et al., 2006). A amorapreta contém pectina em abundância, uma fibra solúvel que ajuda a reduzir os níveis de colesterol no sangue, atuando na prevenção de enfermidades cardiovasculares e circulatórias (NESS; POWLES, 1997; STOCLET et al., 2004). Ainda, esta fruta

'(Trabalho 063-11). Recebido em: 24-01-2011. Aceito para publicação em:02-08-2011.

${ }^{2}$ PhD., Embrapa Clima Temperado, BR 392, Km 78, C. P. 403, CEP 96010-971. Pelotas-RS. E-mail: marcia.vizzotto@cpact.embrapa.br ${ }^{3}$ Nutricionista, mestranda em Ciência e Tecnologia de Alimentos da Universidade Federal do Rio Grande do Sul. Porto Alegre-RS. E-mail: marinacoutopereira@hotmail.com 
atenua os riscos e sintomas do diabetes e do mal de Alzheimer (HERTOG et al., 1997; ISHIGE et al., 2001; ABDILLE et al., 2005).

Existe uma quantidade considerável de trabalhos que avaliam teores de compostos fenólicos em alimentos, porém poucos são os que descrevem adaptações do procedimento para extração em matrizes específicas e/ou condições críticas de preparo de amostra para a quantificação (SOUZA et al., 2009).

Desta forma, este estudo foi conduzido com o propósito de otimizar o processo de extração de compostos fenólicos da amora-preta e a verificação de sua atividade antioxidante, uma vez que o processo de extração para distintas matrizes e analitos é fundamental para a estimativa mais exata.

\section{MATERIAL E MÉTODOS}

Preparo de Amostras: A amora-preta cultivar Tupy, proveniente da Embrapa Clima Temperado (Pelotas-RS), foi colhida e armazenada em freezer a $-18^{\circ} \mathrm{C}$ até o momento das análises (em torno de um mês de armazenamento), quando foram selecionadas por tamanho e cor. Para cada ensaio, foram utilizadas 100 frutas. Destas frutas foi retirada para as análises uma amostra de $5 \mathrm{~g}$ composta apenas pelas suas porções equatoriais, após cortá-las manualmente com faca de cozinha. As amostras foram submetidas a vários testes (descritos a seguir) visando à máxima extração dos compostos fenólicos. Para todos os testes, as amostras foram preparadas em triplicatas, trituradas em um homogeneizador do tipo ultraturrax, dimensionado para amostras pequenas e centrifugadas em centrífuga refrigerada com temperatura em torno de $4^{\circ} \mathrm{C}$ a $15.000 \mathrm{rpm}$. O sobrenadante foi retido para as análises de compostos fenólicos totais e atividade antioxidante.

Relação amostra:solvente: para realização deste ensaio, manteve-se fixo o peso de amostra ( $5 \mathrm{~g}$ de amora-preta) e variou-se o volume do solvente (10mL, 20mL, 30mL, $40 \mathrm{~mL}$ e $50 \mathrm{~mL}$ de metanol). Foi realizada uma única extração para cada amostra.

Período de maceração: para este ensaio, foram utilizados $20 \mathrm{~mL}$ de metanol como solvente. Após a homogeneização das amostras, estas foram submetidas a variados períodos de maceração, anteriormente à centrifugação. Os períodos de maceração foram de $0 ; 2 ; 4 ; 6$ e 24 horas. As amostras foram mantidas ao abrigo da luz durante todo o período de maceração.

Tipos de solventes: para cada $5 \mathrm{~g}$ de amora, foram utilizados $20 \mathrm{~mL}$ dos seguintes solventes (todos os solventes foram testados puros): água ultrapura, metanol, etanol, acetona e hexano.
Misturas de Solventes: utilizou-se de $5 \mathrm{~g}$ de amora-preta com a mistura dos seguintes solventes: 70\% metanol:30\% água ultrapura; 70\% etanol:30\% água ultrapura; 50\% metanol:50\% etanol; 45\% metanol:45\% etanol: $10 \%$ água ultrapura; $45 \%$ metanol:45 etanol: $10 \%$ acetona.

Acidificação dos solventes: os solventes utilizados para este teste foram a água ultrapura, metanol e etanol. As concentrações de $\mathrm{HCl}$ avaliadas para acidificar os solventes foram $0,15 \%, 0,10 \%$, $0,01 \%$ e $0,005 \%$.

Análise de Fenólicos Totais: a metodologia utilizada para determinação de compostos fenólicos totais foi adaptada de Swain e Hillis (1959). Resumidamente, para cada tubo de ensaio, foram pipetados $250 \mu \mathrm{L}$ da amostra, adicionados $4 \mathrm{~mL}$ de água ultrapura e $250 \mu \mathrm{L}$ do reagente Folin-Ciocalteau $(0,25 \mathrm{~N})$, foram agitados e mantidos por 3 minutos para reagir. Após, adicionaram-se $500 \mu \mathrm{L}$ de carbonato de sódio $(1 \mathrm{~N})$, que novamente foram agitados e mantidos por 2 horas para reagir. $\mathrm{O}$ espectrofotômetro foi zerado com o controle (branco) e foram feitas as leituras da absorbância no comprimento de onda de $725 \mathrm{~nm}$. Para a quantificação dos compostos fenólicos, foi construída uma curva-padrão com ácido clorogênico no intervalo de concentração de 0,05 a $0,50 \mu \mathrm{g} / \mathrm{mL}$.

Análise de Atividade Antioxidante: a metodologia utilizada para a determinação da atividade total foi adaptada de Brand-Williams et al. (1995). Em resumo, foram pipetados $200 \mu \mathrm{L}$ de amostra e misturados com $3.800 \mu \mathrm{L}$ de DPPH (diluído em metanol) em tubos de $15 \mathrm{~mL}$ com tampa. Os tubos foram agitados e deixados para reagir por 24 horas. Para a leitura no espectrofotômetro, usou-se o metanol para zerar o equipamento, e a absorbância foi medida no comprimento de onda de $525 \mathrm{~nm}$. Para a quantificação da atividade antioxidante total, uma curva-padrão para o trolox (ácido 6-hidroxi-2,5,7,8tetrametilcroman-2-carboxílico) foi construída no intervalo de concentração de 0,1 a 2,0 mM/mL.

\section{RESULTADOS E DISCUSSÃO}

O primeiro passo para otimizar a metodologia de extração foi determinar a relação ideal entre o volume de solvente utilizado e a massa da amostra. Para este ensaio preliminar, assim como para avaliar o período de maceração, utilizou-se o metanol, solvente amplamente utilizado para extração de fitoquímicos. Variando o volume do solvente metanol entre $10 \mathrm{~mL}$ e $50 \mathrm{~mL}$, não foi observada diferença estatística ( $>0,005)$ para o teor de compostos fenólicos totais (Tabela 1). No entanto, o uso de $40 \mathrm{~mL}$ resultou em atividade antioxidante superior aos demais volumes 
utilizados apesar dos valores não terem diferido estatisticamente daqueles obtidos utilizando $20 \mathrm{~mL}$, $30 \mathrm{~mL}$ e $50 \mathrm{~mL}$ (Tabela 1). Sendo assim, o volume selecionado para as análises seguintes foi de $20 \mathrm{~mL}$; desta forma, extrai-se o máximo de compostos antioxidante com a mínima utilização de solvente possível. A geração de resíduos em laboratório é um grave problema ambiental e deve ser reduzido ao mínimo sem perder a eficiência de extração. Normalmente, a relação considerada eficiente para extração de compostos fenólicos é de 3:1, ou seja, três partes de solvente para uma parte de amostra fresca;mas, em alguns casos, essa relação pode ser ainda menor. Em estudo anterior foi comparada a extração de compostos fenólicos em uma única etapa e em múltiplas etapas, e foi observado que não houve diferenças significativas entre as duas formas de extração (CHIRINOS et al., 2007), sendo que, em etapa única, há redução de tempo de mão de obra.

Várias metodologias utilizadas consideram importante o período de maceração, no qual a amostra fica em contato com a solução extratora, melhorando a eficiência da extração;no entanto, para amora-preta, não foi constatado diferença estatística entre amostras que variaram o período de maceração de 0 (zero) a 24 horas, quando homogeneizadas com o solvente metanol, tanto para a análise de compostos fenólicos totais, quanto para a determinação da atividade antioxidante (Tabela 2). Esse resultado é, bastante interessante, pois evidencia que mais amostras podem ser analisadas em menor período, não existindo qualquer necessidade de realizar maceração, o que torna o método mais fácil, rápido e barato.

Vários solventes foram testados para extração de compostos fenólicos em amora-preta. O teor de compostos fenólicos totais e a atividade antioxidante variaram em função do solvente utilizado (Tabela 3 ). Nas amostras em que se utilizou o solvente hexano (solvente de menor polaridade), não foram detectados compostos fenólicos totais, não sendo possível determinar a atividade antioxidante. Estes resultados estão de acordo com outros autores que sugerem que solventes com alta polaridade, como a água, e solventes com polaridade muito baixas, ou apolares, como hexano ou diclorometano, não são bons extratores (LIU et al., 2000). Acetona foi o solvente mais eficiente em extração, seguido de metanol e etanol, que não diferiram entre si. Desta forma, os compostos fenólicos da amora-preta apresentam características moderadamente polares. O metanol é largamente utilizado para extração de compostos fenólicos com eficiência (TSAO; DENG, 2004; SHI et al., 2005). Metanol e acetona também são indicados para extração de antocianinas de diversas matérias-primas
(SKREDE et al., 2000). A água pura como solvente extrator não foi tão eficiente quando os demais solventes testados (exceto o solvente hexano). Esta, considerada o solvente universal, em combinação com outros solventes orgânicos contribui para criar um meio moderadamente polar, o que favorece a extração de polifenóis (LAPORNIK et al., 2005; LIYANA-PATHIRANA; SHAHIDI, 2005). No entanto, o uso de água pura resulta em extratos com alta impureza (ácidos orgânicos, açúcares, proteínas solúveis), podendo interferir na quantificação destes compostos (CHIRINOS et al., 2007). Apesar de, neste estudo, a acetona mostrar-se mais eficiente, este solvente apresenta vários inconvenientes, principalmente o fato de ser um produto que tem a compra controlada; por esta razão, optou-se buscar alternativas melhorando a eficiência dos outros solventes testados, como o metanol e o etanol.

$\mathrm{Na}$ busca pela melhoria na eficiência do solvente extrator, foram utilizadas misturas dos solventes que haviam sido testados previamente isolados; no entanto, não foi encontrada diferença estatística( $p>0,05)$ para teor de compostos fenólicos totais e atividade antioxidante total, dentre as misturas testadas (Tabela 4).

Outra opção para melhorar a eficiência do solvente extrator é acidificá-lo. Foram utilizados três solventes extratores: a água, o metanol e o etanol, e a acidificação, utilizando $\mathrm{HCl}$, variou de $0,005 \%$ a $0,15 \%$ deste composto. Na acidificação da água, apesar de se observar um aumento dos teores de compostos fenólicos com aumento da acidez, não houve diferença estatística( $p>0,05)$. Para atividade antioxidante, foi observado o inverso, uma redução desta com o aumento da acidez. No entanto, também não houve diferenças estatísticas $(p>0,05)$. Na acidificação do metanol, observou-se uma variação do teor de compostos fenólicos e da atividade antioxidante, mas não foram significativos( $(p>0,05)$. Já, utilizando etanol acidificado, apesar de não haver diferenças para o teor de compostos fenólicos totais, houve aumento da atividade antioxidante quando se utilizou o etanol a $0,01 \%$ de $\mathrm{HCl}$, mostrando que etanol acidificado apresenta melhor capacidade extratora para compostos antioxidantes (Tabela 5). 
TABELA 1 - Compostos fenólicos totais e atividade antioxidante de amora-preta extraídos com diferentes volumes do solvente metanol.

\begin{tabular}{ccc}
\hline $\begin{array}{c}\text { Volume } \\
(\mathrm{mL})\end{array}$ & $\begin{array}{c}\text { Compostos fenólicos totais } \\
(\mathrm{mg} / 100 \mathrm{~g})\end{array}$ & $\begin{array}{c}\text { Atividade } \text { antioxidante }^{2} \\
(\mu \mathrm{g} / \mathrm{g})\end{array}$ \\
\hline 10 & $609 *(159)^{\mathrm{ns}}$ & $7438(277) \mathrm{b}$ \\
20 & $515(90)$ & $7861(477) \mathrm{ab}$ \\
30 & $574(49)$ & $8174(203) \mathrm{ab}$ \\
40 & $607(36)$ & $9436(1026) \mathrm{a}$ \\
50 & $647(43)$ & $9059(1152) \mathrm{ab}$ \\
\hline
\end{tabular}

* Médias seguidas das mesmas letras na vertical não diferem significativamente ao nível de erro de $5 \%$ pelo teste de tukey. ( ) número entre parêntese representa o desvio padrão. Ns- não significativo. 1Compostos fenólicos totais expressos em mg equivalente ácido clorogênico/100g de amostra fresca. 2Atividade antioxidante expressa em $\mu \mathrm{g}$ equivalente de trolox/g de amostra fresca.

TABELA 2 - Compostos fenólicos totais e atividade antioxidante de amora-preta, extraídos com metanol, utilizando diferentes tempos de maceração.

\begin{tabular}{ccc}
\hline Tempo de extração $(\mathrm{h})$ & $\begin{array}{c}\text { Compostos fenólicos totais } \\
(\mathrm{mg} / 100 \mathrm{~g})\end{array}$ & $\begin{array}{c}\text { Atividade antioxidante } \\
(\mu \mathrm{g} / \mathrm{g})\end{array}$ \\
\hline 0 & $608^{*}(119)^{\mathrm{ns}}$ & $7291(1491)^{\mathrm{ns}}$ \\
2 & $627(62)$ & $7788(1020)$ \\
4 & $675(54)$ & $7969(1046)$ \\
6 & $692(96)$ & $7883(997)$ \\
24 & $652(36)$ & $8023(1160)$
\end{tabular}

* Médias seguidas das mesmas letras na vertical não diferem significativamente ao nível de erro de $5 \%$ pelo teste de tukey. ( ) número entre parêntese representa o desvio padrão. Ns- não significativo. 1Compostos fenólicos totais expressos em mg equivalente ácido clorogênico/100g de amostra fresca. 2Atividade antioxidante expressa em $\mu \mathrm{g}$ equivalente de trolox/g de amostra fresca.

TABELA 3 - Fenólicos totais e atividade antioxidante em amora-preta utilizando diferentes solventes.

\begin{tabular}{ccc}
\hline Solventes & $\begin{array}{c}\text { Compostos fenólicos totais } \\
(\mathrm{mg} / 100 \mathrm{~g})\end{array}$ & $\begin{array}{c}\text { Atividade antioxidante } \\
(\mu \mathrm{g} / \mathrm{g})\end{array}$ \\
\hline Água & $427 *(23) \mathrm{c}$ & $4279(207) \mathrm{c}$ \\
Metanol & $672(58) \mathrm{b}$ & $7207(625) \mathrm{b}$ \\
Etanol & $711(28) \mathrm{b}$ & $8064(301) \mathrm{b}$ \\
Acetona & $1022(46) \mathrm{a}$ & $12109(817) \mathrm{a}$ \\
Hexano & $0 \mathrm{~d}$ & $0 \mathrm{~d}$ \\
\hline
\end{tabular}

* Médias seguidas das mesmas letras na vertical não diferem significativamente ao nível de erro de 5\% pelo teste de tukey. ( ) número entre parêntese representa o desvio padrão. Ns- não significativo. 1Compostos fenólicos totais expressos em mg equivalente ácido clorogênico/100g de amostra fresca. 2Atividade antioxidante expressa em $\mu \mathrm{g}$ equivalente de trolox/g de amostra fresca.

TABELA 4 - Fenólicos totais e atividade antioxidante em amora-preta usando misturas de solventes na extração.

\begin{tabular}{ccc}
\hline Misturas de solventes & $\begin{array}{c}\text { Compostos fenólicos totais }^{1} \\
(\mathrm{mg} / 100 \mathrm{~g})\end{array}$ & $\begin{array}{c}\text { Atividade } \\
\text { antioxidante }^{2}(\mu \mathrm{g} / \mathrm{g})\end{array}$ \\
\hline Metanol:água 70:30 & $745^{*}(62)^{\mathrm{ns}}$ & $7071(2263)^{\mathrm{ns}}$ \\
Etanol:água 70:30 & $705(50)$ & $7765(684)$ \\
Metanol:etanol 50:50 & $896(119)$ & $7632(381)$ \\
Metanol:etanol:água 45:45:10 & $844(95)$ & $8146(296)$ \\
Metanol:etanol:acetona 45:45:10 & $1179(117)$ & $8877(1050)$ \\
\hline
\end{tabular}

* Médias seguidas das mesmas letras na vertical não diferem significativamente ao nível de erro de 5\% pelo teste de tukey. ( ) número entre parêntese representa o desvio padrão. Ns- não significativo. 1Compostos fenólicos totais expressos em mg equivalente ácido clorogênico/100g de amostra fresca. 2Atividade antioxidante expressa em $\mu \mathrm{g}$ equivalente de trolox/g de amostra fresca. 
TABELA 5 - Fenólicos Totais e Atividade Antioxidante em amora-preta usando solventes acidificados para extração.

\begin{tabular}{ccccccc}
\hline $\begin{array}{c}\text { Acidez } \\
(\%)\end{array}$ & $\begin{array}{c}\text { Compostos } \\
\text { fenólicos }^{1} \\
(\mathrm{mg} / 100 \mathrm{~g})\end{array}$ & $\begin{array}{c}\text { Atividade } \\
\text { antioxidante }^{2} \\
(\mu \mathrm{g} / \mathrm{g})\end{array}$ & $\begin{array}{c}\text { Compostos } \\
\text { fenólicos }^{1} \\
(\mathrm{mg} / 100 \mathrm{~g})\end{array}$ & $\begin{array}{c}\text { Atividade } \\
\text { antioxidante }^{2}(\mu \mathrm{g} / \mathrm{g})\end{array}$ & $\begin{array}{c}\text { Compostos } \\
\text { fenólicos }^{1} \\
(\mathrm{mg} / 100 \mathrm{~g})\end{array}$ & $\begin{array}{c}\text { Atividade } \\
\text { antioxidante }^{2} \\
(\mu \mathrm{g} / \mathrm{g})\end{array}$ \\
\hline \multicolumn{2}{c}{ Água } & \multicolumn{2}{c}{ Metanol } & \multicolumn{2}{c}{ Etanol } \\
\hline 0,15 & $537 *(40)^{\mathrm{ns}}$ & $5759(161)^{\mathrm{ns}}$ & $787(97)^{\mathrm{ns}}$ & $8602(1541)^{\mathrm{ns}}$ & $805(60)^{\mathrm{ns}}$ & $7877(370) \mathrm{b}$ \\
0,10 & $452(82)$ & $5872(39)$ & $813(24)$ & $7171(665)$ & $800(23)$ & $7685(342) \mathrm{b}$ \\
0,01 & $437(11)$ & $5924(14)$ & $752(19)$ & $7866(678)$ & $747(28)$ & $8670(176) \mathrm{a}$ \\
0,005 & $272(211)$ & $6223(821)$ & $826(41)$ & $8602(421)$ & $815(105)$ & $7564(214) \mathrm{b}$ \\
\hline
\end{tabular}

* Médias seguidas das mesmas letras na vertical não diferem significativamente ao nível de erro de $5 \%$ pelo teste de tukey. ( ) número entre parêntese representa o desvio padrão. Ns- não significativo. 1Compostos fenólicos totais expressos em mg equivalente ácido clorogênico/100g de amostra fresca. 2Atividade antioxidante expressa em $\mu \mathrm{g}$ equivalente de trolox/g de amostra fresca.

\section{CONCLUSÕES}

1-O protocolo mais prático, e econômico, sem redução de eficiência foi utilização de acetona como solvente, centrifugação imediata da amostra sem necessidade de maceração ou de acidificação.

2- Uma outra opção, sem uso de acetona, que tem a compra controlada, seria o uso de etanol acidificado a $0,01 \%$.

\section{REFERÊNCIAS}

ABDILLE, M. H.; SINGH R. P.; JAYAPRAKASHA, G. K.; JENA, B. S. Antioxidant activity of the extracts from Dillenia indica fruits. Food Chemistry, Washington, v. 90, p. 891-896, 2005.

ANTUNES, L. E. C. Amora - Preta: Nova Opção de Cultivo no Brasil. Ciência Rural, Santa Maria, v. 32, n. 1, 2002.

BRAND-WILLIAMS, W.; CUVELIER, M. E.; BERSET, C. Use of a free radical method to evaluate antioxidant activity. Lebensmittel-Wissenschaft und Technologie, London, v. 28, p. 25-30, 1995.

CHIRINOS, R.; ROGEZ, H.; CAMPOS, D.; PEDRESCHI, R.; LARONDELLE, Y. Optimization of extraction conditions of antioxidant phenolic compounds from mashua (Tropaeolum tuberosum Ruiz \& Pavon) Tubers. Separation and Purification Technology, Amsterdam, v. 55, p. 217-225, 2007.
DING, M.; FENG, R.; WANG, S. Y.; BOWMAN, L.; LU, Y.; QIAN, Y.; CASTRANOVA, V.; JIANG, B-H.; SHI, X. Cyanidin-3-glucoside, a Natural Product Derived from Blackberry, Exhibits Chemopreventive and Chemotherapeutic Activity. Journal of Biological Chemistry, Maryland, v. 281, n. 25, p. 1.7359-1.7368, 2006.

HERTOG, M. G. L.; SWEETNAM, P. M.; FEHILY, A. M.; ELWOOD, P. C.; KROMHOUT, D. Antioxidant flavonols and ischemic heart disease in a Welsh population of men. The Caterphilly study. American Journal of Clinical Nutrition, Houston, v. 65, p. 1489-1494, 1997.

ISHIGE, K.; SCHUBERT, D.; SAGARA, Y. Flavonoids protect neuronal cells from oxidative stress by three distinct mechanisms. Free Radical Biological Medicine, Washington, v. 30, p. 433-446, 2001.

LAPORNIK, B.; PROŠEK, M.; WONDRA, A. G. Comparison of extract prepared from plant byproducts using different solvents and extraction time. Journal of Food Engineering, London, v. 71, p. 214-501, 2005.

LAZZE, M. C.; SAVIO, M.; PIZZALA, R.; CAZZALINI, O.; PERUCCA, P.; SCOVASSI, A. I.; STIVALA, L. A.; BIANCHI, L. Anthocyanins induce cell cycle perturbations and apoptosis in different human cell lines. Carcinogenesis, Oxford, v. 25, n. 8, p. 1.427-1.433, 2004.

LIU, F. F.; ANG, C. Y. W.; SPRINGER, D. Optimization of extraction conditions for active components in Hypericum perforatum using surface methodology. Journal of Agriculture and Food Chemistry, Washington, v. 48, p. 3.364-3.371, 2000. 
LIYANA-PATHIRANA, C.; SHAHIDI, F. Optimization of extraction of phenolics compounds from wheat using response surfase methodology. Food Chemistry, Washington, v. 93, p. 45-56, 2005.

NESS, A. R.; POWLES, J. W. Fruit and vegetables, and cardiovascular disease: a review. International Journal of Epidemiology, Oxford, v. 26, n. 1, p. $1-13,1997$.

SEERAM, N. P.; ADAMS, L. S.; ZHANG, Y.; LEE, R.; SAND, D.; SCHEULLER, H. S.; HEBER, D. Blackberry, black raspberry, blueberry, cranberry, red raspberry, and strawberry extracts inhibit growth and stimulate apoptosis of human cancer cells in vitro. Journal of Agricultural and Food Chemistry, Washington, v. 54, p. 9.329-9.339, 2006.

SELLAPPAN, S.; AKOH, C. C.; KREWER, G. Phenolic compounds and antioxidant capacity of Georgia-grown blueberries and blackberries. Journal of Agricultural and Food Chemistry, Washington, v. 50 , p. $2.432-2.438,2002$.

SHI, J.; NAWAZ, H.; POHORLY, J.; MITTAL, G.; KAKUDA, I.; JIANG, Y. Extraction of polyphenolics from plant material for functional foods-engineering and technology. Food Reviews International, New York, v. 21, p. 139-166, 2005.
SKREDE, G.; WORLSTAD, R. E.; DURST, R. W. Changes in anthocyanins and polyphenolics during juice processing of Highbush blueberries (Vaccinium corymbosum L.). International Journal of Food Science \& Technology, Washington, v. 65, p. $357-$ 364, 2000.

SOUZA, M. M. de; RECART, V. M.; ROCHA, M. da R.; CIPOLATTI, E. P.; BADIALE-FURLONG, E. Estudo das condições de extração de compostos fenólicos de cebola (Allium cepa L.). Revista Instituto Adolfo Lutz, São Paulo, v. 68, n. 2, 2009.

STOCLET, J. C.; CHATAIGNEAU, T.; NDIAYE, M.; OAK, M. H.; EL BEDOUI, J.; CHATAIGNEAU, M.; SCHINI-KERTH, V. B. Vascular protection by dietary polyphenols. European Journal of Pharmacology, Washington, v. 500, p. 299-313, 2004.

SWAIN, T.; HILLIS, W. E. The phenolic constituents of Prunus domestica I.- The quantitative analysis of phenolic constituents. Journal of Science and Food Agriculture. Washington, v. 10, p. 63-68, 1959.

TATE, P.; STANNER, A.; SHIELDS, K.; SMITH, S.; LARCOM, L. Blackberry extracts inhibit UVinduced mutagenesis in Salmonella typhimurium TA100. Nutrition Research, Amsterdam,, v. 26, p. 100-104, 2006.

TSAO, R.; DENG, Z. Separation procedures for naturally occurring antioxidant phytochemicals. Journal of Chromatography B, Washington, v. 812 , p. 85-99, 2004 